\title{
Evaluation of Extended (D2) Lymphadenectomy for Treatment of Gastric Cancer
}

\author{
Hossam Abdelkader, ${ }^{1} M D$; Haitham Elmaleh, ${ }^{2} M R C S, M D$; \\ Rabbah Abdellateef,2 MD; Ismael Morad ${ }^{3}, M D$
}

\author{
1) Department of General surgery, Menofia University, Menofia, Egypt. \\ 2) Department of General surgery, Ain Shams University, Cairo, Egypt. \\ 3) Department of Surgical oncology, National Cancer Institute, Cairo, Egypt.
}

Background \& objectives: Although gastric cancer is one of the most common causes of cancer-related death, its prognosis remains poor. Surgical resection with lymph node dissection is the only potentially curative therapy for gastric cancer. However, the appropriate extent of lymph node dissection remains controversial. In East Asian countries, D2 lymph node dissection has been performed as a standard procedure. In western countries, D2 dissection was associated with higher mortality and morbidity with no 5-year survival benefit compared to D1 dissection. More recent studies have demonstrated that western surgeons can be trained to perform D2 lymphadenectomies on achieving survival benefits comparable to those of reported in eastern countries. The aim of our study is to evaluate the feasibility, safety and outcome of extended (D2) lymphadenectomy for gastric cancer.

Patients and methods: Between July 2008 and June 2014, patients with gastric cancer in whom surgical resection was indicated, were prospectively included in this study. Enrolled patients underwent gastrectomy with D2 lymphadenectomy. The patients were followed up regularly after the operation. Postoperative parameters, disease-specific mortality \& KaplanMeier survival analysis were used to assess the outcomes.

Results: 62 patients were included in the study. 33 patients had distal gastrectomy and 29 patients had total gastrectomy. 9 (14.5\%) patients had postoperative complications with 2 cases of postoperative mortality recorded. The overall mean survival time was $17.13 \pm 9.6$ months and the disease free mean survival time was $13.4 \pm 9.39$ months. Kaplan-Meier survival analysis showed that the overall survival probability estimate in the study was $100 \%$ at 1 year, $88.7 \%$ at 2 years, $58.1 \%$ at 3 years and $32.3 \%$ at 4 years. Nodal disease class \& $N$ stage were found to have a statistically significant effect on survival.

Conclusion: D2 lymphadenectomy can be performed safely in well-equipped hospitals by experienced surgeons with acceptable morbidity \& mortality. It can provide better survival for patients with gastric cancer and low degree of lymph node metastases (N1 or NO).

Key words: Stomach cancer, D2 lymphadenectomy, extended lymphadenectomy.

\section{Introduction:}

Gastric cancer is one of the most common causes of cancer-related death ${ }^{1}$ and is second only to lung cancer worldwide. ${ }^{2}$ The wide variation in incidence between eastern and western countries strongly suggests an ethnic background as a risk factor. Egypt falls into the low risk area, with an incidence of 2.9 per
100,000, in comparison to 5.3 per 100.000 populations in the United States. These rates are 5 to 15 times lower than in Japan, where the overall incidence is 50 per 100.000 population. ${ }^{2}$ The prognosis of gastric cancer patients remains poor, with a 5-year overall survival of $25 \%$ or less, especially in the USA, Europe, and China. ${ }^{3}$ Lymph node metastasis 
is an important prognostic indicator for the patients with gastric cancer. Surgical resection with lymph node dissection is the only potentially curative therapy for gastric cancer. However, the appropriate extent of lymph node dissection to be performed with gastrectomy remains controversial. ${ }^{4}$ The 5 year survival rate reported in most western series is $10 \%$ to $21 \%$, which is a consequence of high proportion of patients that present in advanced stages. ${ }^{5}$ In East Asian countries, especially Japan and Korea, D2 lymph node dissection has been regularly performed as a standard procedure. In Western countries, surgeons used to perform gastrectomy with D1 dissection only because D2 dissection was associated with higher mortality and morbidity with no 5-year survival benefit compared to D1 dissection.6,7 However, more recent studies have demonstrated that western surgeons can be trained to perform D2 lymphadenectomies on western patients with a lower morbidity and mortality, and eventually achieving survival benefits comparable to those of reported in eastern counties. ${ }^{8,9,10}$ The question of whether these results can be repeated in Egypt is still a matter of research. The aim of our study is to evaluate the feasibility, safety and outcome of performing extended (D2) lymphadenectomy for gastric cancer in Egypt.

\section{Patients and methods:}

The study was conducted in three hospitals in Egypt (National cancer Institute, Menofyia university hospitals \& Ain Shams university hospitals) between July 2008 and June 2014, and it was a prospective interventional study. It included patients with gastric cancer in whom surgical resection was indicated.

Preoperative workup involved laboratory investigations (complete blood picture, renal functions, liver functions, serum electrolytes \& coagulation profile); chest X-rays, enhanced computed tomography scans of the abdomen and pelvis, and gastric endoscopy and biopsy. All tumors were diagnosed as adenocarcinomas by histopathological assessment of biopsy specimens.

We used the $\mathrm{D}$ terminology according to the guidelines of Japanese Research Society for Gastric Cancer (JRSGS). According to this classification, lymph nodes surrounding stomach are divided into 20 stations and these are classified into three groups depending upon the location of the primary tumor. This grouping system is based on the results of studies of lymphatic flow at various tumor sites, together with the observed survival associated with metastasis to each nodal station. In this grouping system, most perigastric LNs (Right paracardial, Left paracardial, Right and left gastric, Right and Left gastro-omental, Suprapyloric, and Subpyloric LNs [stations no. 1-6 respectively]) are defined as group 1, whereas the nodes along the left gastric artery (station no. 7), common hepatic artery (station no. 8), celiac axis (station no. 9), splenic artery (station no. 11) and hepato-dudenal ligament (station no. 12) are defined as group 2. D1 gastrectomy is defined as dissection of all the Group 1 nodes (plus station 7), and D2 is defined as dissection of all the Group 1 and Group 2 nodes. ${ }^{11}$

All our patients underwent D2 lymphadenectomy, splenectomy was done for greater curve lesion attached to the spleen. No pancreatectomy was done.

All patients had follow-up visits after discharge from hospital every 3 months for the first year, and twice a year thereafter. The routine examination during followup included a physical examination, blood chemistry tests, chest X-ray, abdominal ultrasound. Pelvi-abdominal CT, bone scan and endoscopy were done for selected patients when indicated.

We used disease-specific mortality for controlling of unrelated causes of death. Stratified and Cox regression analyses were used to evaluate the association between survival and the number of positive node harvested. The parameters analyzed included operative time, blood loss, blood transfusion, morbidity, number of harvested lymph nodes (HLNs), number of positive LN, T stage, and overall survival. Kaplan-Meier survival analysis was conducted to measure the survival estimates and assess the effect 

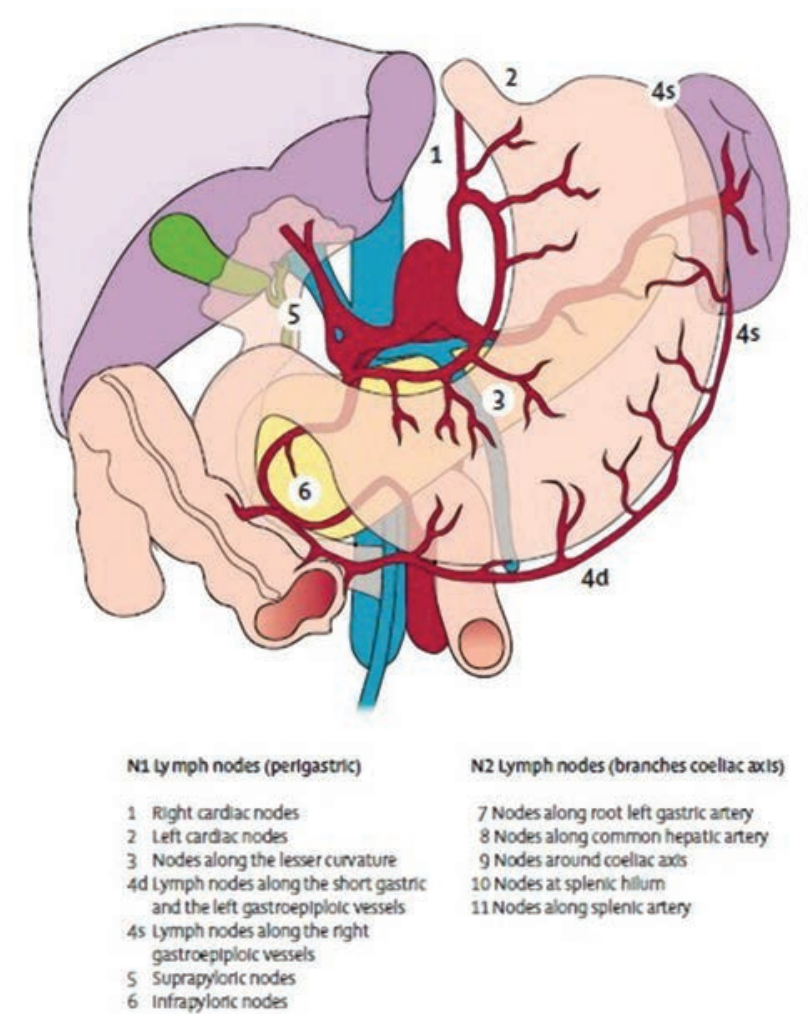

N2 Lymph nodes (branches coellac axis)

7 Nodes along root left gastric antery 8 Nodes along common hepatic arten 9 Nodes around coellac aes 11 Noder along splenic antery

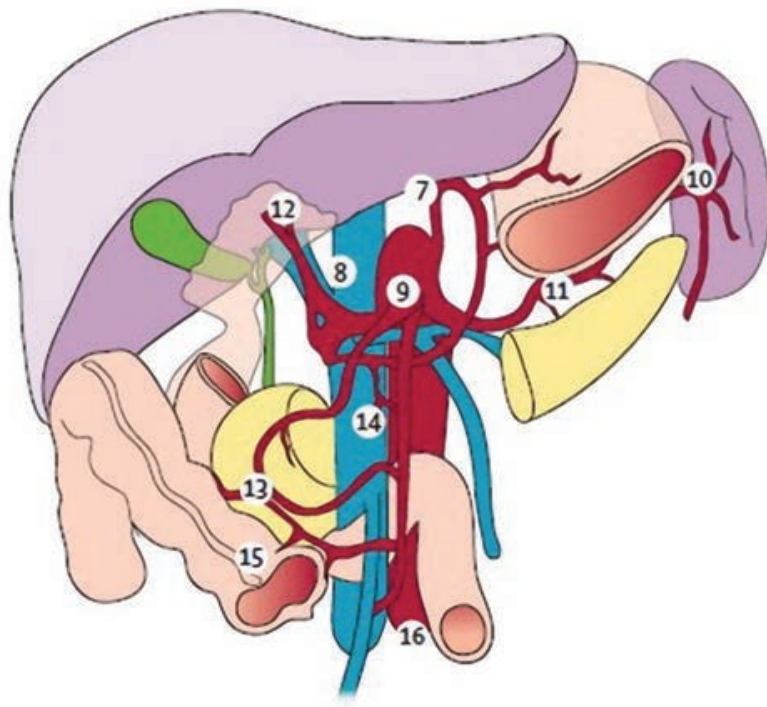

N3 Lymph nodes

12 Nodes at the hepatoduodenal ligarnent 13 Retropancreatic (penduodenal) nodes 14 Nodes at the root of the mesenteny
N4 Lymph nodes

15 Nodes along the middle colk vein 16 Para-aortik nodes

Figure (1): Location and grouping of the lymph nodes. D1 resection: Removal of the N1 lymph nodes. D2 resection: Removal of the N1 and N2 lymph nodes. \{Quoted from Songun et al. $\left.{ }^{12}\right\}$

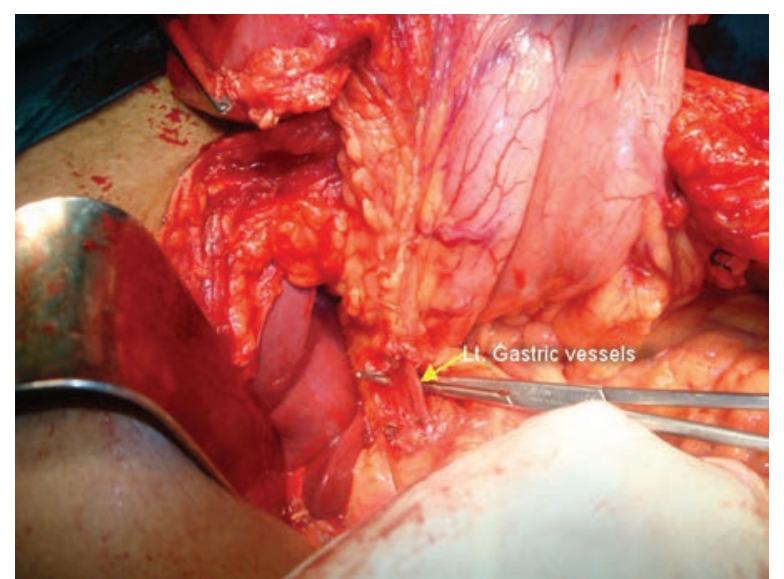

Figure (2): Intraoperative view of dissection of LNs along left gastric vessels (group 7).

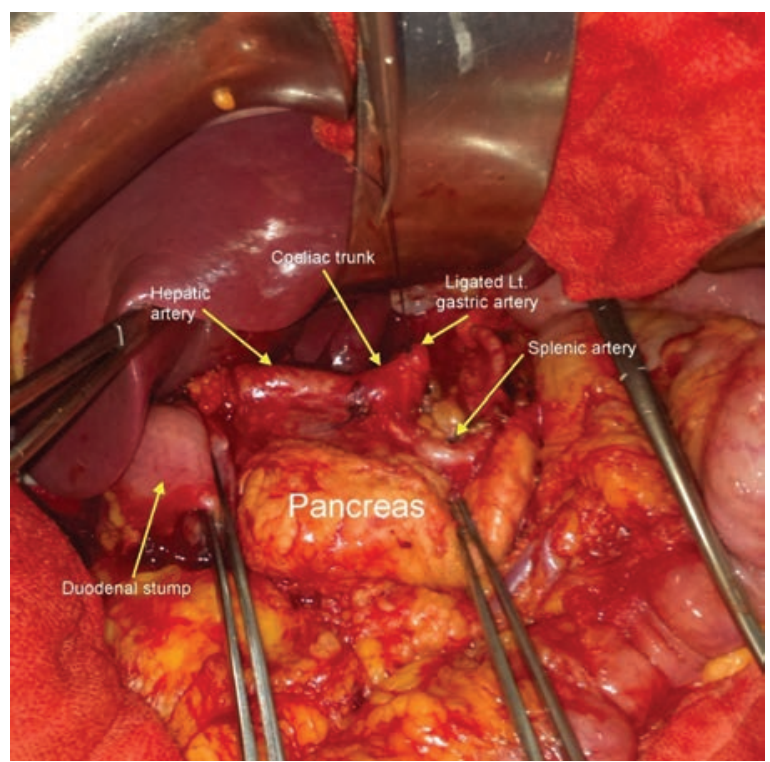

Figure (3): Intraoperative view of the field after dissection of LNs along the coeliac, hepatic, splenic \& left gastric arteries (groups 7, $8,9 \& 10)$.

the mean age of patients was $52.29 \pm 15.08$ (range: 24-75) years.

According to the 7th AJCC's TNM staging system for gastric cancer, there were 10,5 , 19 and 28 patients in the N0, N1, N2 and N3 stage, respectively. Patients with low nodal 

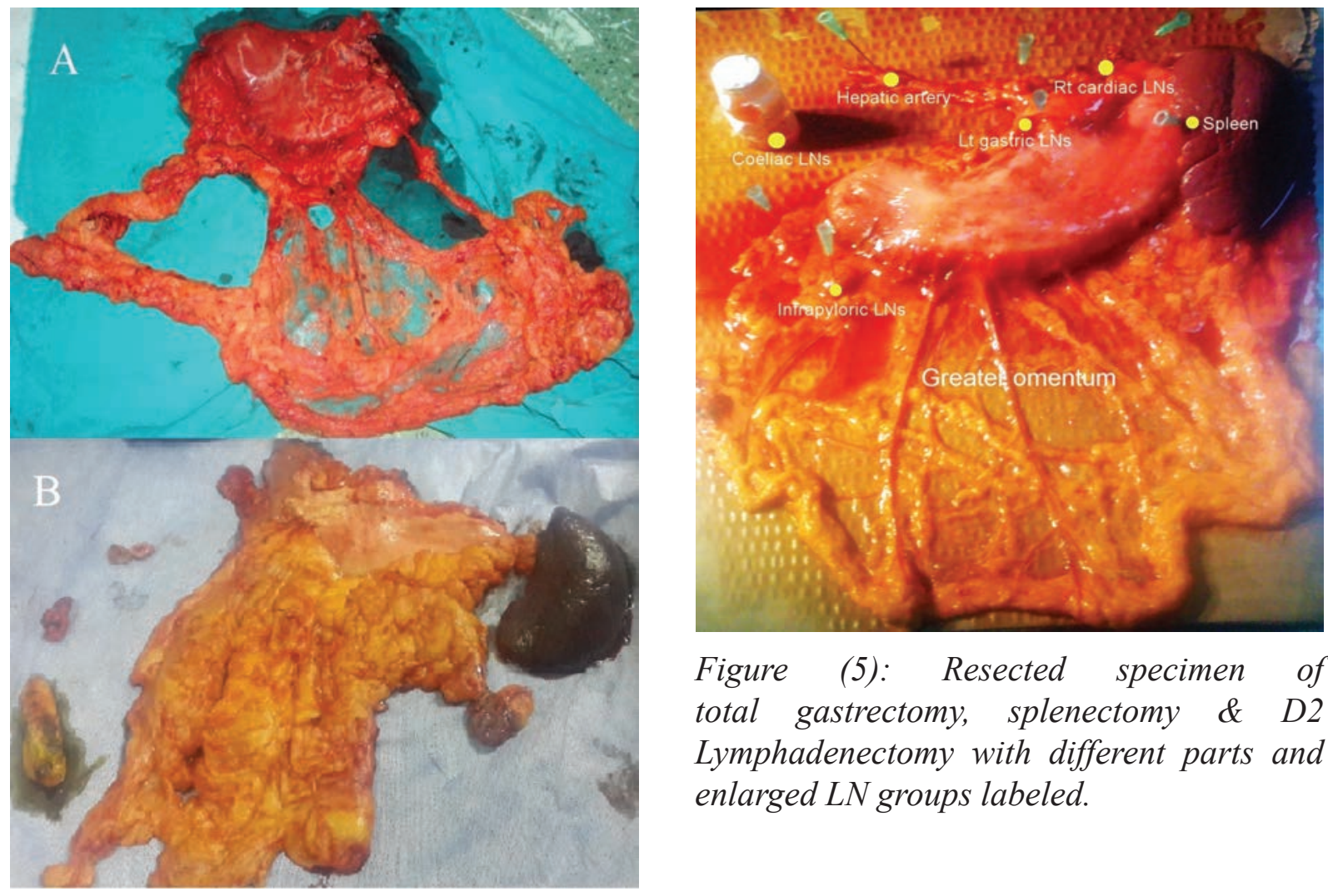

Figure (5): Resected specimen of total gastrectomy, splenectomy \& D2 Lymphadenectomy with different parts and enlarged LN groups labeled.

Figure (4): Resected specimens of: A: Distal gastrectomy, B: Total gastrectomy \& splenectomy both with extended lymphadenectomy.

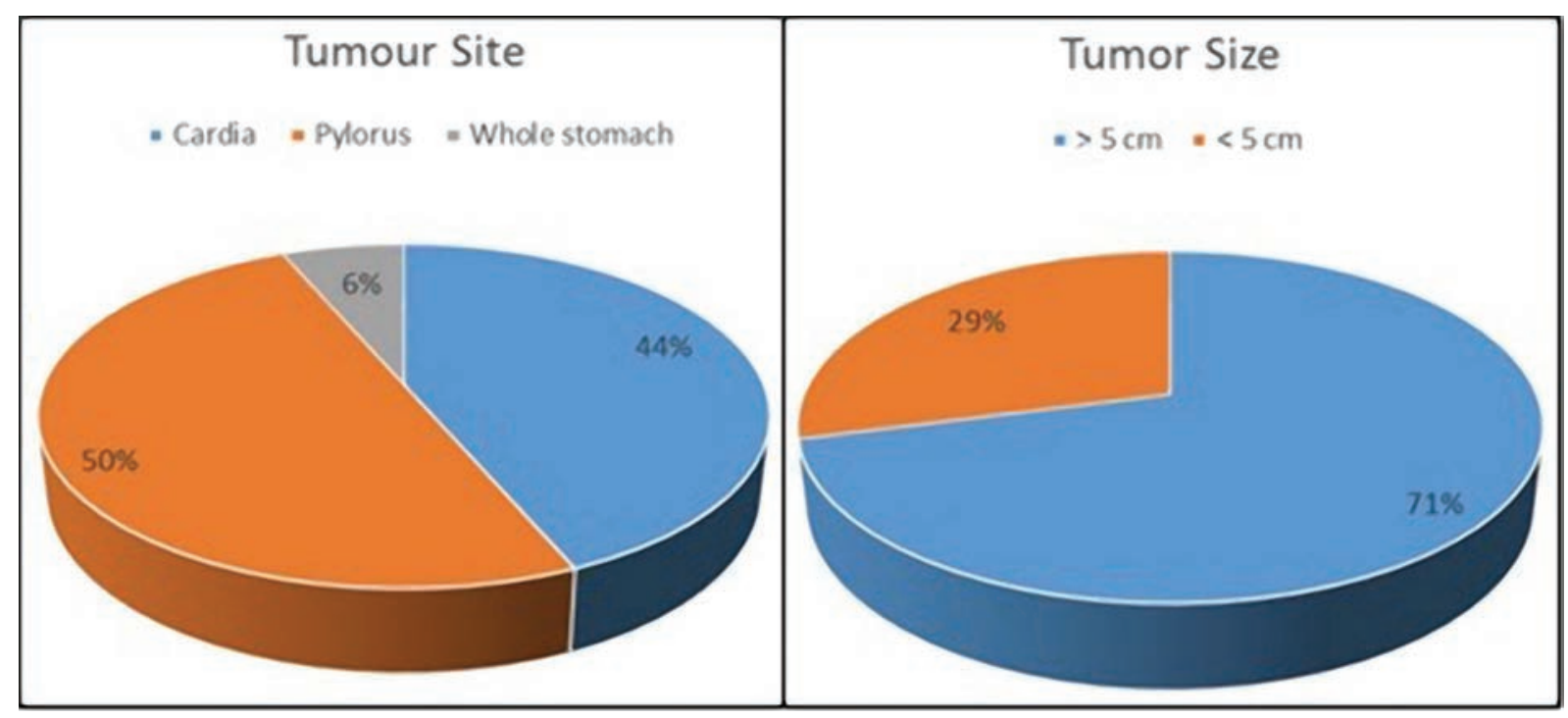

Figure (6): Tumor site \& size distribution in the study group.

disease ( $\mathrm{N} 0$ or 1 ) were 15 and were termed early nodal disease patients, high or late nodal disease patients were 47 . There were 9 , 32 and 21 patients in the T2, T3 and T4 stage, respectively. The patients' clinicopathological characteristics are shown in Figures (6-8).

33 patients had distal gastrectomy and
29 patients had total gastrectomy. D2 LN dissection was done in all cases. No intraoperative mortality was recorded. The mean average number of lymph nodes harvested was 33 \pm 5 nodes (range: 21-41). The details of operative data are shown in Table (1). 


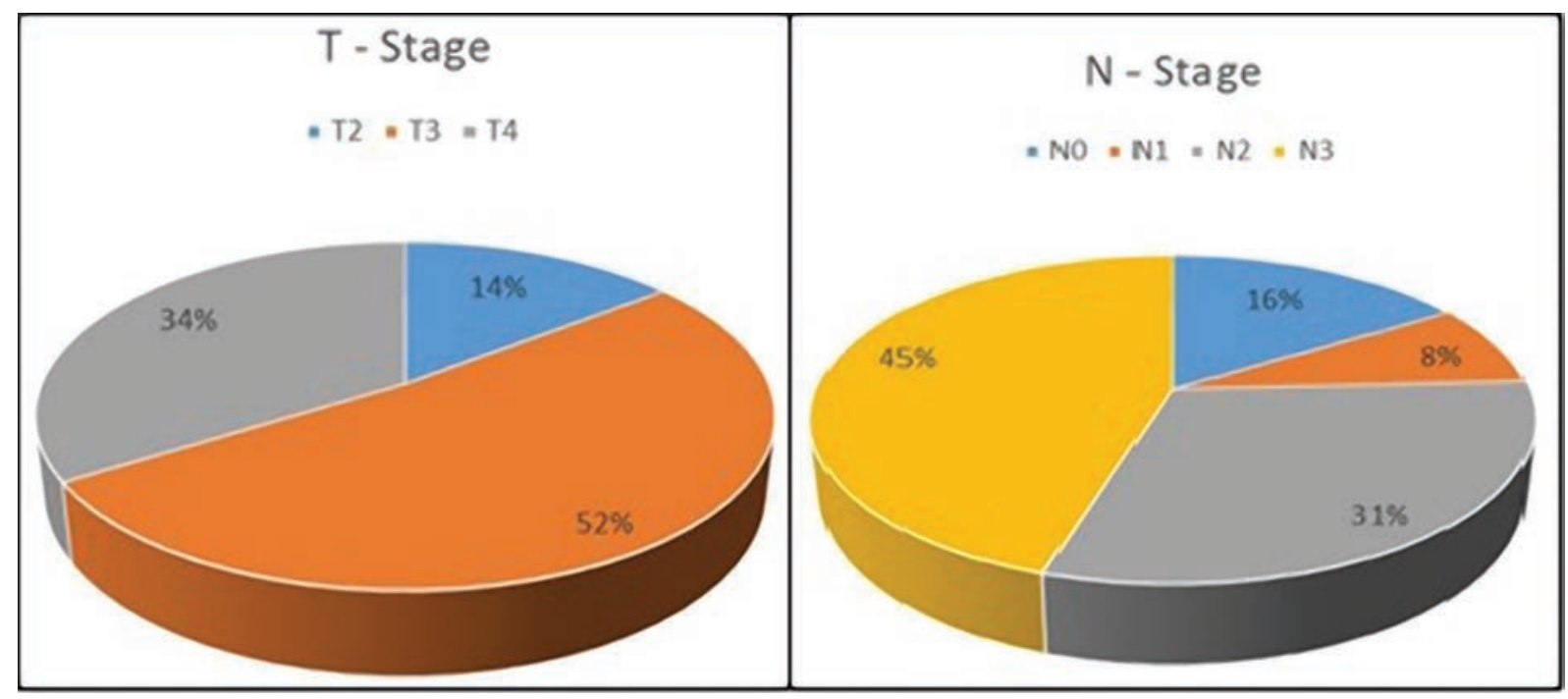

Figure (7): $T$ \& $N$ stages distribution in the study group.

\section{Nodal Disease Class}

$$
\text { - Early - Late }
$$

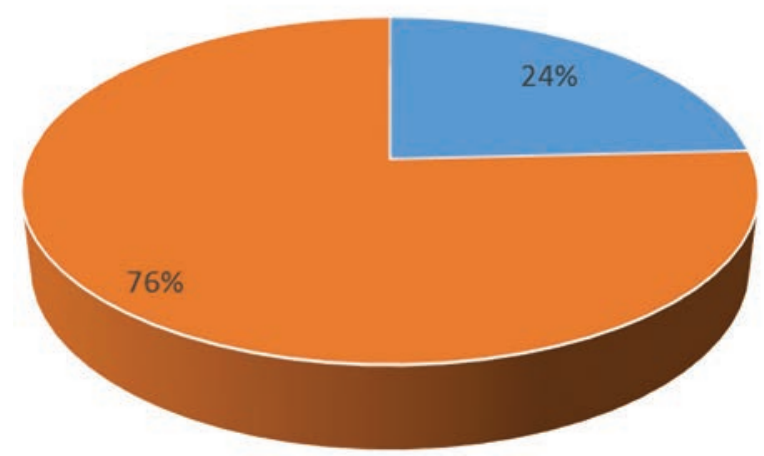

Figure (8): Nodal disease class distribution in the study group.

\section{Postoperative Complications}

$$
\text { - Leakage - Duodenal stump blowout - Pneumonia = Wound infection - None }
$$

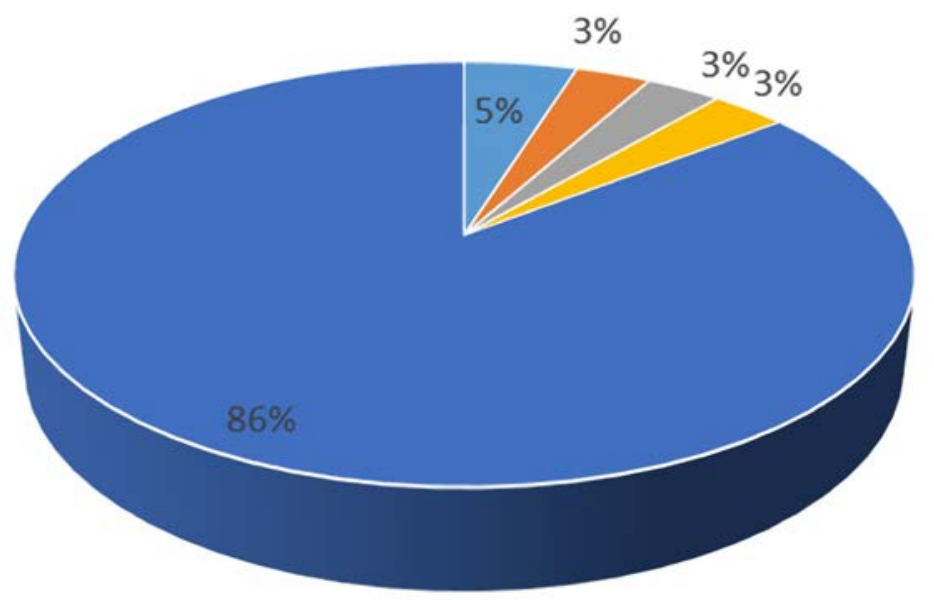

Figure (9): Post operative complications in the study group. 
Survival Status at End of Study

- Alive - Dead

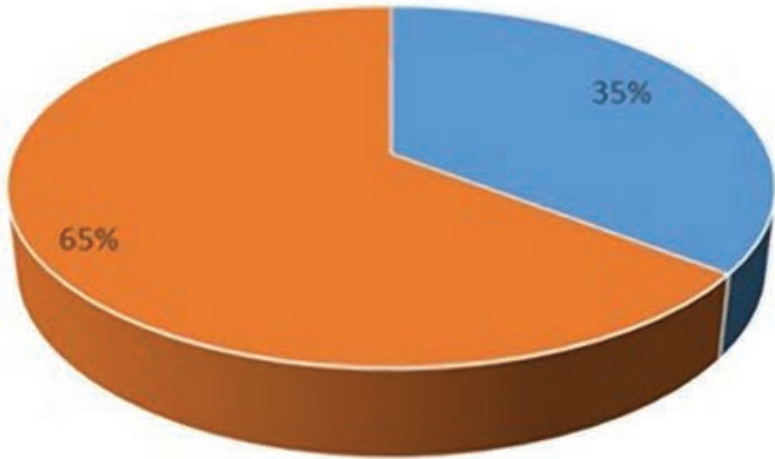

\section{Recurrence Status}

- No recurrence - Recurrence

\section{Recurrence Metastasis Site}

$\begin{array}{llll}\text { - Bone } & \text { - Liver } & \text { = Lung } & \text { - Peritonium } \\ \text { = Local } & \text { = Chest Wall } & \text { - Pleura } & \text { = Liver \& Bone }=\text { Liver \& Lung }\end{array}$

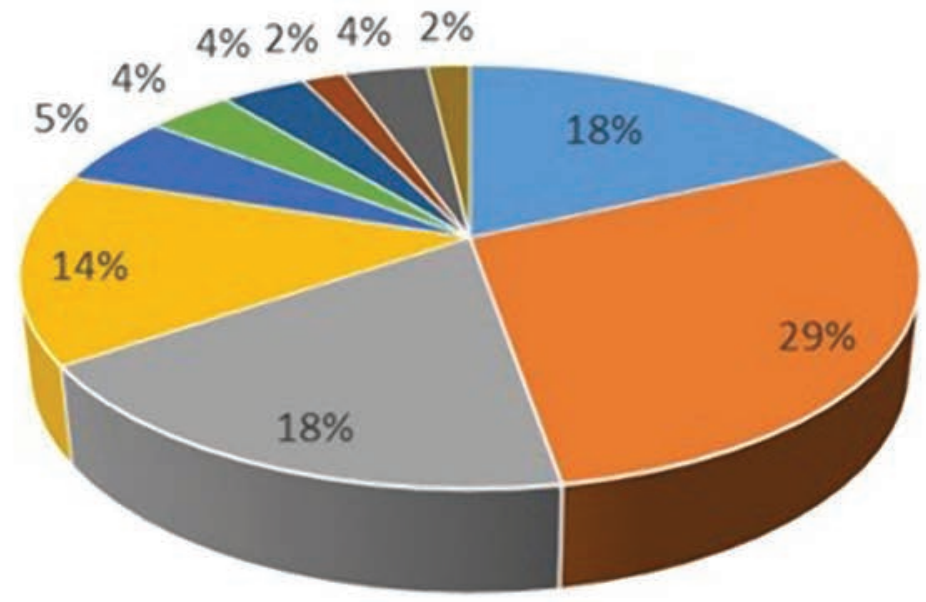

Figure (10): Survival \& recurrence data in the study.

The mean follow-up period in our study was 32 months (range 12-48 months). 9 (14.5\%) Patients had postoperative complications (3 cases of leakage from esophagojejunal anastomosis after total gastrectomy, 2 duodenal stump blowouts, 2 wound infection and 2 cases of pneumonia). Two cases (3.2\%) of mortality were recorded in the first month after surgery (one after leakage from esophagojejunal anastomosis and 1 after duodenal stump blowout). Postoperative complications are shown in Figure (9).

The overall mean survival time was 17.13 \pm 9.6 months. The disease free mean survival time was $13.4 \pm 9.39$ months. Kaplan-Meier survival analysis showed that the overall survival probability estimate in the study to be $100 \%$ at 1 year, $88.7 \%$ at 2 years, $58.1 \%$ at 3 years and $32.3 \%$ at 4 years. The majority of cases with recurrence had systemic metastasis not local recurrence. In addition, most of the cases of disease related death were from systemic metastasis not local recurrence. Follow up data are shown in Table (2) and Figure (10).

Statistical analysis was done in order to define the relation between disease parameters and survival pattern with $\mathrm{D} 2$ resection. 


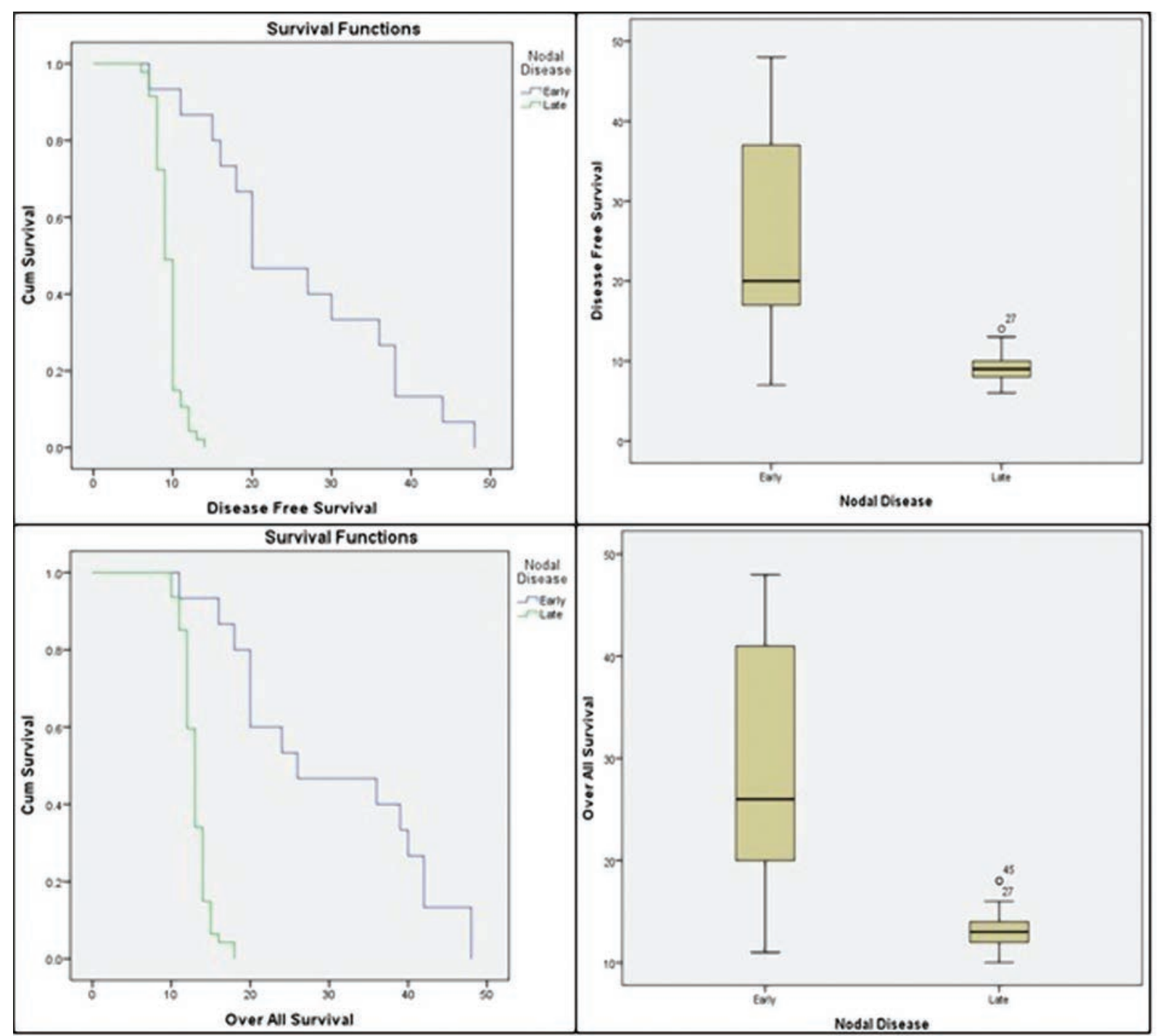

Figure (11): Kaplan-Meier survival analysis curves of the relation between LNs status and survival.

Relation between the numbers of harvested lymph nodes and survival: Cox regression analysis revealed that there was no significant relation between the number of harvested LN and overall survival or disease free survival as shown in Table (3).

Relation between lymph node status and survival: We categorized the patients in study by their metastatic lymph node status into early nodal disease group (N0 and 1) and late nodal disease group (N2 and 3).

Kaplan-Meier survival analysis showed a highly significant difference in disease free and overall survival between early and late nodal disease. The mean disease free survival times were $25.87 \pm 3.23$ and 9.42 \pm 0.23 months for early and late nodal groups respectively, and the mean overall survival times were $30 \pm 3.24$ and $13.02 \pm 0.25$ months for early and late nodal groups respectively as shown in Table (4) and Figure (11).

Relation between the $\mathrm{N}$ stages and survival:

Kaplan-Meier survival analysis showed a highly significant difference in disease free survival and overall survival between different nodal stages. The median disease free survival times were 30, 16, 9 and 9 months for N0, N1, N2 and N3 respectively. The median overall survival times were 39, 18, 13 and 13 months for N0, N1, N2 and N3 respectively, as shown in Table (5) and Figure (12).

\section{Discussion:}

The proper surgical management of 


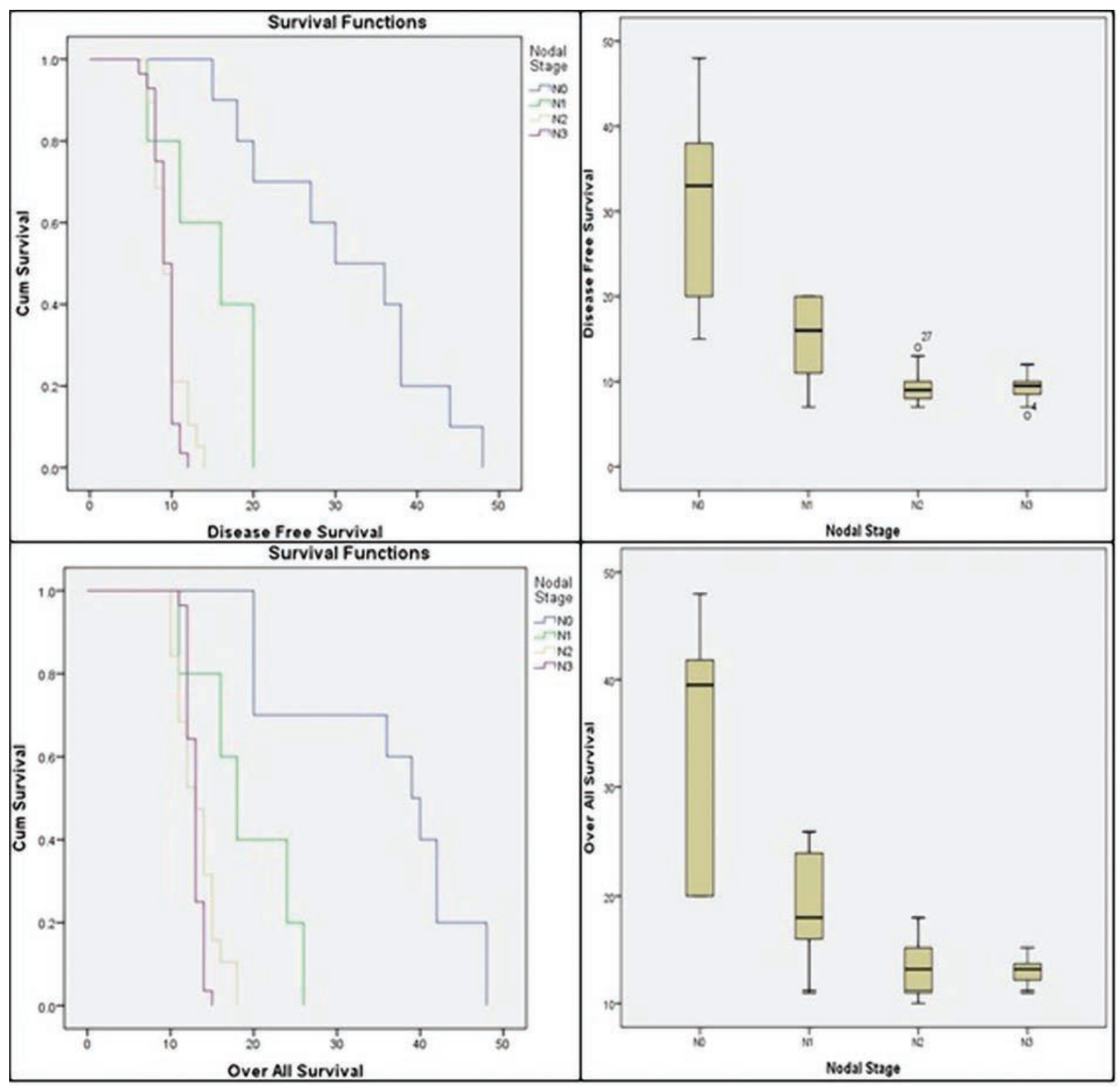

Figure (12): Kaplan-Meier survival analysis curves of the relation between LNs status and disease free survival.

Table (1): Operative data in the study group.

\begin{tabular}{|c|c|c|c|c|c|}
\hline \multicolumn{2}{|l|}{ Item } & Mean & $\begin{array}{c}\text { Std. } \\
\text { Deviation }\end{array}$ & Minimum & Maximum \\
\hline \multicolumn{2}{|l|}{ Total LNs harvested } & 33 & 5 & 21 & 41 \\
\hline \multirow{2}{*}{ Operative time } & $\begin{array}{l}\text { Distal } \\
\text { gastrectomy }\end{array}$ & 127.8 & 19.1 & 96 & 180 \\
\hline & $\begin{array}{l}\text { Total } \\
\text { gastrectomy }\end{array}$ & 155.1 & 25.9 & 120 & 220 \\
\hline \multirow{2}{*}{$\begin{array}{l}\text { Intraoperative blood } \\
\text { loss }\end{array}$} & $\begin{array}{l}\text { Distal } \\
\text { gastrectomy }\end{array}$ & 105.9 & 54.7 & 50 & 250 \\
\hline & $\begin{array}{l}\text { Total } \\
\text { gastrectomy }\end{array}$ & 193 & 93 & 50 & 400 \\
\hline
\end{tabular}


Table (2): Survival data in the study.

\begin{tabular}{|l|l|l|l|l|}
\hline \multicolumn{1}{|c|}{ Item } & Minimum & Maximum & Mean & Std. Deviation \\
\hline Over all survival & 10 & 48 & 17.13 & 9.601 \\
\hline Disease free survival & 6 & 48 & 13.40 & 9.390 \\
\hline
\end{tabular}

\begin{tabular}{|l|l|}
\hline \multicolumn{1}{|c|}{ Time } & \multicolumn{1}{c|}{ Survival probability estimate } \\
\hline 1 Month & 100 \\
\hline 1 Year & 88.7 \\
\hline 2 Years & 58.1 \\
\hline 3 Years & 46.2 \\
\hline 4 Years & 32.3 \\
\hline
\end{tabular}

Table (3): Cox regression analysis of the relation between harvested LNs and survival.

\begin{tabular}{|l|c|c|l|l|l|}
\hline & B & SE & Wald & P value & Odds Ratio \\
\hline Overall Survival & -.016 & .032 & .251 & .616 & .984 \\
\hline Disease Free Survival & -.022 & .028 & .641 & .423 & .978 \\
\hline
\end{tabular}

Table (4): Kaplan-Meier survival analysis of the relation between LNs status and disease free survival.

\begin{tabular}{|c|c|c|c|c|c|c|c|}
\hline \multirow{3}{*}{ Survival } & \multirow{3}{*}{$\begin{array}{c}\text { Nodal } \\
\text { disease }\end{array}$} & \multicolumn{4}{|c|}{ Mean } & \multicolumn{2}{|c|}{ Median } \\
\hline & & \multirow{2}{*}{ Estimate } & \multirow{2}{*}{$\begin{array}{l}\text { Std. } \\
\text { Error }\end{array}$} & \multicolumn{2}{|c|}{ 95\% Confidence interval } & \multirow{2}{*}{ Estimate } & \multirow{2}{*}{\begin{tabular}{|c|} 
Std. \\
Error
\end{tabular}} \\
\hline & & & & Lower Bound & Upper Bound & & \\
\hline \multirow{3}{*}{ Disease free } & Early & 25.867 & 3.231 & 19.535 & 32.199 & 20.000 & 4.347 \\
\hline & Late & 9.426 & .229 & 8.976 & 9.875 & 9.000 & .254 \\
\hline & Overall & 13.403 & 1.193 & 11.066 & 15.741 & 10.000 & .233 \\
\hline \multirow[t]{3}{*}{ Overall } & Early & 30.000 & 3.241 & 23.647 & 36.353 & 26.000 & 10.305 \\
\hline & Late & 13.021 & .254 & 12.524 & 13.518 & 13.000 & .271 \\
\hline & Overall & 17.129 & 1.219 & 14.739 & 19.519 & 13.000 & .375 \\
\hline
\end{tabular}

stomach cancer had been subjected to much debates for years. Despite that, controversy still exists regarding the role of extended lymphadenectomy in the treatment of gastric cancer. ${ }^{5}$ Radical lymphadenectomy was adopted based on an initial report published in 1981 by Kodama and his colleagues who described a survival benefit for patient with serosal or regional lymph node involvement who underwent D2 or D3 lymphadenectomy. ${ }^{13}$ There have been significant differences in Eastern and Western philosophies regarding the role and extent of lymph node dissection for gastric cancer. The Eastern view generally contends that extensive lymphadenectomy provides better cancer clearance and therefore improves survival, whereas the Western view generally holds that lymphadenectomy provides prognostic information and when done adequately, improves staging and guides adjuvant treatment decisions. From either perspective, there is strong agreement that lymphadenectomy is an integral part of highquality gastric cancer operation, but debates are still present that eastern results of better survival can be reproduced in other parts of the world. ${ }^{14}$ Our study tried to address this point from the practice point of view in Egypt.

In our study, 62 patients with stomach cancer underwent D2 lymphadenectomy 
Table (5): Kaplan-Meier survival analysis of the relation between $N$ stage and survival.

\begin{tabular}{|c|c|c|c|c|c|c|c|}
\hline \multirow{3}{*}{ Survival } & \multirow{3}{*}{$\begin{array}{l}\text { Nodal } \\
\text { stage }\end{array}$} & \multicolumn{4}{|c|}{ Mean } & \multicolumn{2}{|c|}{ Median } \\
\hline & & \multirow[b]{2}{*}{ Estimate } & \multirow{2}{*}{$\begin{array}{l}\text { Std. } \\
\text { Error }\end{array}$} & \multicolumn{2}{|c|}{ 95\% Confidence interval } & \multirow[b]{2}{*}{ Estimate } & \multirow{2}{*}{$\begin{array}{l}\text { Std. } \\
\text { Error }\end{array}$} \\
\hline & & & & $\begin{array}{l}\text { Lower } \\
\text { bound }\end{array}$ & $\begin{array}{l}\text { Upper } \\
\text { bound }\end{array}$ & & \\
\hline \multirow{5}{*}{$\begin{array}{l}\text { Disease } \\
\text { free }\end{array}$} & N0 & 31.400 & 3.563 & 24.417 & 38.383 & 30.000 & 7.115 \\
\hline & N1 & 14.800 & 2.557 & 9.788 & 19.812 & 16.000 & 5.477 \\
\hline & N2 & 9.632 & .447 & 8.755 & 10.508 & 9.000 & .484 \\
\hline & N3 & 9.286 & .240 & 8.814 & 9.757 & 9.000 & .294 \\
\hline & Overall & 13.403 & 1.193 & 11.066 & 15.741 & 10.000 & .233 \\
\hline \multirow[t]{5}{*}{ Overall } & No & 35.500 & 3.575 & 28.492 & 42.508 & 39.000 & 3.162 \\
\hline & N1 & 19.000 & 2.720 & 13.668 & 24.332 & 18.000 & 2.191 \\
\hline & N2 & 13.211 & .580 & 12.073 & 14.348 & 13.000 & .933 \\
\hline & N3 & 12.893 & .173 & 12.553 & 13.232 & 13.000 & .208 \\
\hline & Overall & 17.129 & 1.219 & 14.739 & 19.519 & 13.000 & .375 \\
\hline
\end{tabular}

in 3 large referral hospitals by experienced surgical teams. All cases were completed without intraoperative morbidity or mortality. The mean average number of lymph nodes harvested was $33 \pm 5$ nodes. 9 (14.5\%) Patients had postoperative complications (3 anastomotic leakage, 2 duodenal stump blowout, 2 wound infection and 2 had pneumonia). Two cases (3.2\%) of mortality were recorded in the first month after surgery. The overall mean survival time was 17.13 \pm 9.6 months. The disease free mean survival time was $13.4 \pm 9.39$ months. $89 \%$ of patients had recurrence during the follow up period. The overall survival probability estimate in the study was $100 \%$ at 1 year, $88.7 \%$ at 2 years, $58.1 \%$ at 3 years and $32.3 \%$ at 4 years.

Comparing our results to the published literature outside Japan. In 2006, Wu and his colleagues ${ }^{15}$ from Taiwan published their randomized controlled trial of D1 versus “D3" dissection in Lancet Oncology. The D3 lymphadenectomy described in this study essentially included a JGCA D2 lymphadenectomy together with nodes around the retropancreatic region and superior mesenteric vein. The study included 221 patients, and the primary endpoints were 5-year overall- and disease-free survival. At a median follow-up of 95 months, there was a 5-year overall survival rate of $63 \%$ for patients who underwent D3 surgery and $58 \%$ for patients undergoing D1 surgery ( $p$ $=0.006$ ). The recurrence rate at 5 years was $51 \%$ after D1 surgery and 40\% after D3 surgery. 15 The Dutch Gastric cancer Group had a study of 711 patients undergoing surgical treatment of stomach cancer, their first results were published at 2004. In 2010, the Dutch trial was updated with a 15-year follow-up results. ${ }^{12}$ Gastric cancer-related death was 37\% for the D1 group and 48\% for the D2 group ( $\mathrm{p}=0.01$ ), whereas death from other causes was the same in both groups. ${ }^{12}$ Hanna and his colleagues published in 2012 their experience with D2 gastrectomy. ${ }^{16}$ From 2003 to 2010, 100 patients underwent gastrectomy. He reported anastomotic leak rate of $2 \%$. Postoperative mortality and technical complications for gastric cancer resections were similar to Japanese rates. Kaplan-Meier estimates of overall survival after gastrectomy was $90.6 \%$ at 1 year, $74.3 \%$ at 2 years, $67.8 \%$ at 3 years, $64 \%$ at 4 years and $58.4 \%$ at 5 years. ${ }^{16}$ The early postoperative morbidity and mortality results in our study are higher than those published in the studies mentioned. Also, our survival results especially after 2 years are significantly worse than those reviewed being only close to those of the Dutch trial. That can be explained by two reasons. First, the majority of our patients 
had advanced disease (86\% were T stage 3 or 4 and $76 \%$ were $\mathrm{N}$ stage 2 or 3 ). This fact may be the cause of high recurrence rates. Second, the volume of cases is less than those reported in the mentioned trials especially the one done in Taiwan, meaning that we are still in the phase of gaining experience. The higher case volume results in better surgical experience and improved technical expertise leading to better overall results. In spite of that, our study showed that the recurrence was mainly metastatic not local, meaning that D2 lymphadenectomy had actually improved the outcome regarding the local control of the disease.

Lymph node metastasis is one of the most important prognostic factors in gastric cancer. We tried to assess the effect of different parameters related to LN metastases on survival after D2 dissection. Our study found that there was no significant relation between the number of harvested $\mathrm{LN}$ and overall or disease free survival. On the contrary, analysis demonstrated a significant relation between $\mathrm{N}$-stage and survival with patients with late nodal disease ( $\mathrm{N}$ stage 2 or 3) having shorter disease free survival and overall survival times ( 9 and 13 months respectively) than those with early nodal disease despite the extended nodal dissection done. These findings are opposite to those of the Dutch trial, which had found that patients with N2 disease have benefited from the extended lymphadenectomy. ${ }^{12}$

Our study have its limitation. The number of cases is not large enough as other trials and follow up period was variable and no 5 year follow up data were documented.

\section{Conclusion:}

D2 lymphadenectomy can be performed safely in well-equipped hospitals by experienced surgeons with acceptable morbidity and mortality. It can provide hope for better survival for patients with gastric cancer and low degree of lymph node metastases (N1 or N0). Further studies with larger case numbers and longer follow up period are needed to address the limitations of our study.

\section{Reference:}

1- Pisani P, Parkin DM, Bray F, Ferlay J: Estimates of the worldwide mortality from 25 cancers in 1990. International Journal of Cancer 1999; 83(1): 18-29.

2- Freedman LS, Edwards BK, Ries LAG, Young JL (eds): Cancer incidence in four member countries (Cyprus, Egypt, Israel, and Jordan) of the Middle East Cancer Consortium (MECC) compared with US SEER. National Cancer Institute 2006; NIH Pub. No. 06-5873. Bethesda, MD.

3- Jemal A, Siegel R, Ward E, Hao Y, Xu J: Cancer statistics, 2008. CA Cancer J Clin 2008; 58: 71-96.

4- Tamura S, Takeno A, Miki H: Lymph node dissection in curative gastrectomy for advanced gastric cancer. Int $J$ Surg Oncol 2011; 2011: Article ID: 748745, 8 pages.

5- Seevaratnam R, Bocicariu A, Cardoso R, Mahar A, Kiss A, Helyer L, Law C, Coburn $\mathrm{N}$ : A meta-analysis of D1 versus D2 lymph node dissection. Gastric Cancer 2012; 15 Suppl 1: 60-69.

6- Bonenkamp JJ, Songun I, Hermans J, Sasako M, Welvaart K, Plukker JT, van Elk P, Obertop H, Gouma DJ, Taat CW, et al: Randomised comparison of morbidity after D1 and D2 dissection for gastric cancer in 996 Dutch patients. Lancet 1995; 25: 345(8952): 745-748.

7- Cuschieri A, Fayers P, Fielding J, Craven J, Bancewicz J, Joypaul V, Cook P: Postoperative morbidity and mortality after D1 and D2 resections for gastric cancer: Preliminary results of the MRC randomised controlled surgical trial. The Surgical Cooperative Group. Lancet 1996; 13: 347(9007): 995-999.

8- Roviello F, Marrelli D, Morgagni P, de Manzoni G, Di Leo A, Vindigni C, Saragoni L, Tomezzoli A, Kurihara H; (Italian Research Group for Gastric Cancer): Survival benefit of extended D2 lymphadenectomy in gastric cancer with involvement of second level lymph nodes: A longitudinal multicenter study. Annals of Surgical Oncology 2002; 9(9): 894-900.

9- Degiuli M, Sasako M, Calgaro M, Garino M, Rebecchi F, Mineccia M, Scaglione D, Andreone D, Ponti A, Calvo F; (Italian Gastric Cancer Study Group): Morbidity and mortality after D1 and D2 gastrectomy for cancer: Interim analysis of the Italian Gastric Cancer Study Group (IGCSG) randomised 
surgical trial. European Journal of Surgical Oncology 2004; 30(3): 303-308.

10- Dikken JL, Verheij M, Cats A, Jansen EP, Hartgrink HH, van de Velde CJ: Extended lymph node dissection for gastric cancer from a European perspective. Gastric Cancer 2011; 14(4): 396-398.

11- Japanese Gastric Cancer Association. Japanese gastric cancer treatment guidelines 2010 (ver. 3). Gastric Cancer 2011; 14(2): 113-123.

12- Songun I, Putter H, Kranenbarg EM, Sasako M, van de Velde CJ: Surgical treatment of gastric cancer: 15-year follow-up results of the randomized nationwide Dutch D1D2 trial. Lancet Oncol 2010; 11(5): 439-449.

13- Kodama Y, Sugimachi K, Soejima K, Matsusaka T, Inokuchi K: Evaluation of extensive lymph node dissection for carcinoma of the stomach. World J Surg 1981; 5(2): 241-248.

14- Strong VE, Yoon SS: Extended lymphadenectomy in gastric cancer is debatable. World J Surg 2013; 37(8): 1773-1777.

15- Wu CW, Hsiung CA, Lo SS, Hsieh MC, Chen JH, Li AF, Lui WY, Whang-Peng J: Nodal dissection for patients with gastric cancer: A randomised controlled trial. Lancet Oncol 2006; 7(4): 309-315.

16- Hanna GB, Boshier PR, Knaggs A, Goldin $\mathrm{R}$, Sasako M: Improving outcomes after gastroesophageal cancer resection: Can Japanese results be reproduced in Western centers? Arch Surg 2012; 147(8): 738-745. 